\title{
RESEARCH
}

Open Access

\section{High frequencies of PMN-MDSCs are associated with low suppressive capacity in advanced stages of HIV-1 infection}

Eva M. Grützner ${ }^{1,2}$, Ashley Neizert ${ }^{1}$, Renate Stirner ${ }^{1,2}$, Raffaele Conca ${ }^{3}$, Immanuel Andrä ${ }^{4}$, Lisa Wolff, ${ }^{5,2}$, Matthias Schiemann ${ }^{4}$, Lesca M. Holdt ${ }^{6}$, Christoph Klein ${ }^{3}$, Johannes R. Bogner ${ }^{1,2}$ and Rika Draenert ${ }^{1,2^{*}}$

\begin{abstract}
Background: Polymorphonuclear myeloid-derived suppressor cells (PMN-MDSCs) are an immature cell type that inhibits the effector functions of T lymphocytes in chronic HIV infection. A well-known immunological feature of the disease course is the development of immune exhaustion, which is correlated with excessive immune activation in late-stage disease. Here, we hypothesized that immune exhaustion would also affect PMN-MDSCs in late-stage HIV-1 infection.

Methods: We evaluated untreated chronically HIV-infected patients (progressors, $n=10$ ) and control groups (controllers, patients with non-small cell lung carcinoma and healthy controls, $n=16$ ) with regard to levels of PMNMDSCs and their inhibitory potential. Additionally, we studied CD8 T cell effector functions (interferon-gamma, TNF alpha, IL-2 and CD107) and parameters of CD8 T cell activation (CD38 and HLA-DR) and exhaustion (PD-1 and LAG3) by flow cytometry. Plasma inflammation markers analyzed here were IL-6, IL-8, soluble CD14, highly sensitive CRP, and cystatin C.

Results: Coincubation experiments with isolated PMN-MDSCs led to a significant inhibition of CD8 T cell proliferation $(p<0.0001)$, with a significant correlation between PMN-MDSC frequency and suppressive capacity: the higher the frequency of PMN-MDSCs was, the lower the suppressive capacity (rho $=0.51, p=0.0082$ ). Stratifying all study subjects into subgroups with PMN-MDSC frequencies above or below $2.5 \%$ resulted in a significantly increased suppressive capacity in patients with frequencies below $2.5 \%(p=0.021)$. While there was no correlation with the cellular activation markers CD38 and HLA-DR, high IL-8 levels were significantly associated with high PMN-MDSC frequencies ( $r$ ho $=0.52, p=0.0074$ ) and low suppressive capacity ( $r h o=0.47, p=0.019$ ).

Conclusions: In this study, we demonstrate for the first time that PMN-MDSCs show limited effector functions in advanced disease stages of HIV infection. The hyperactive immune state is associated with this loss of function. However, we show an association with the proinflammatory cytokine IL-8, which is an important factor for the migration and adhesion of polymorphonuclear cells.
\end{abstract}

Keywords: Myeloid-derived suppressor cells (MDSCs), HIV-1 infection, CD8 T cell suppression, Immune exhaustion, CD8 T cell proliferation, Immune activation

\footnotetext{
* Correspondence: rika.draenert@med.uni-muenchen.de

'Division of Infectious Diseases, Medizinische Klinik und Poliklinik IV, Ludwig

Maximilian University Hospital of Munich, Pettenkoferstr. 8a, 80336 Munich,

Germany

${ }^{2}$ German Center for Infection Research (DZIF), Munich partner site, Munich,

Germany

Full list of author information is available at the end of the article
}

(c) The Author(s). 2020 Open Access This article is distributed under the terms of the Creative Commons Attribution 4.0 International License (http://creativecommons.org/licenses/by/4.0/), which permits unrestricted use, distribution, and reproduction in any medium, provided you give appropriate credit to the original author(s) and the source, provide a link to the Creative Commons license, and indicate if changes were made. The Creative Commons Public Domain Dedication waiver (http://creativecommons.org/publicdomain/zero/1.0/) applies to the data made available in this article, unless otherwise stated. 


\section{Background}

Human myeloid-derived suppressor cells (MDSCs) represent a heterogeneous group of immature cells that evolve from myeloid progenitor cells and have an immunosuppressive function. Two major subsets of MDSCs have been described: polymorphonuclear (PMN)- and monocytic (M)-MDSCs [1]. PMN-MDSCs, which are the focus of this study, are precursor cells of granulocytes and are therefore expected to resemble this cell type with regard to migration, adhesion and mechanisms of action [1,2]. The immunosuppressive potential of PMN-MDSCs has been described in an oncology context [1-7] and more recently in infectious diseases [8-11]. PMN-MDSCs were shown to accumulate in chronic HIV infection [8, 12]. Significantly higher numbers of PMN-MDSCs have been found in untreated patients with progressive HIV infection (progressors = $\mathrm{PR})$ than in HIV-uninfected/healthy controls (HC), HIV controllers $(\mathrm{CO})$ or antiretroviral-treated patients $[8,13]$. PMN-MDSC frequencies also correlate with markers of disease progression, namely, CD4 $\mathrm{T}$ cell count and viral load. In addition, the suppressive potential of these cells has mostly been shown with regard to $\mathrm{T}$ cell function in chronic progressive HIV infection.

Via their immunoinhibitory actions, MDSCs are presumed to contribute to $\mathrm{T}$ cell exhaustion, which is a well-known hallmark of chronic HIV infection. Immune exhaustion in HIV infection has been the focus of intense research efforts over the past several years. During untreated HIV disease, the polyfunctionality of CD8 T cells declines and therefore their ability to proliferate and to produce the cytokines CD107a, IL-2, TNF alpha and interferon-gamma diminishes. Consequently, the immune system loses the ability to control the infection, and the disease progresses towards the AIDS stage. Immune exhaustion has been demonstrated for several parts of the immune system; however, it is not known if this exhaustion also affects MDSCs [14-22].

Immune exhaustion in HIV disease is inseparably linked to excessive immune activation, which also correlates with disease progression [23, 24]. This excessive activation contributes to high $\mathrm{T}$ cell turnover and can be measured by cellular and soluble factors, e.g., the expression of CD38 and HLA-DR on T cells. Additionally, the elevated plasma levels of proinflammatory cytokines such as interferon-gamma type 1, IL-6, IL- 8 and TNF alpha and the increased serum markers of inflammation CRP, cystatin C and sCD14 are indicative of intense immune activation in HIV infection $[25,26]$. IL-8, also called CXCL8, is a member of the chemokine family and interacts with the cellular receptors CXCR1 and CXCR2. IL-8 is an important factor for the migration and activation of polymorphonuclear cells, which include PMNMDSCs. In the context of HIV infection, IL- 8 has been studied extensively and has been shown to be a marker of immune activation in HIV disease with relevance to polymorphonuclear cells [27-35].

In the present study, we evaluated the suppressive capacity of human PMN-MDSCs in different disease stages and entities and studied the association of suppressive capacity with markers of immune activation (IL-8 among others) and immune exhaustion, as well as with the effector functions of HIV-specific CD8 T cells.

\section{Methods}

\section{Study subjects}

Twenty-six individuals participated in the study after signing informed consent. The study was approved by the Institutional Review Board of the LudwigMaximilian-Universität, Munich, Germany (project number: 227-11). The study subjects were divided into the following groups:

PR (progressors: untreated patients with chronic HIV infection; $n=10$ ): defined by a CD4 cell count less than $400 / \mu \mathrm{l}$ and a viral load (VL) greater than 10,000 copies/ $\mathrm{ml}$. These patients were newly diagnosed and started antiretroviral treatment directly after the study blood draw. The median CD4 count was $80 / \mu$ l (range 4-355/ $\mu \mathrm{l}$ ), and the median VL was 276,802 copies/ml (range 2100 - 5,999,674 copies/ml).

CO (controllers: patients who had controlled the HIV infection spontaneously in the absence of HAART for more than 4 years; $n=5$ ): defined by a CD4 cell count above 500/ $\mu \mathrm{l}$ and a VL below 2000 copies/ml (including elite controllers (EC): patients with a VL below 40 copies/ml; $n=3$ ). The median CD4 count was $923 / \mu l$ (range $644-1085 / \mu \mathrm{l})$, and the median VL was 40 copies $/ \mathrm{ml}$ (range 40-1940 copies/ml).

We included an exception to these definitions: PR 1 had a low CD4 cell count of 80 cells/ $\mu \mathrm{l}$, and therefore, we accepted a low-level viremia of 2100 copies $/ \mathrm{ml}$.

BRO $(n=6)$ : patients with advanced-stage non-small cell lung carcinoma (NSCLC) before specific treatment; disease stage III or IV; and HIV-uninfected.

$\mathrm{HC}$ (healthy controls; $n=5$ ).

PBMCs (peripheral blood mononuclear cells) of additional HIV-uninfected subjects were used as target cells for proliferation assays. These volunteers also signed informed consent.

The characteristics of the study subjects are summarized in Table 1.

\section{Blood processing}

For cytokine staining, freshly obtained EDTA blood was centrifuged, and the obtained plasma was frozen at $80^{\circ} \mathrm{C}$. Then, PBMCs were isolated by Ficoll density gradient centrifugation (Biocoll Separation Solution, Biochrom, Germany). Frequencies of PMN-MDSCs were 
Table 1 Characteristics of the study subjects at blood draw

\begin{tabular}{llllllr}
\hline & $\begin{array}{l}\text { CD4 cell count } \\
(\text { median, cells/ } \mu l)\end{array}$ & range & $\begin{array}{l}\text { HIV-RNA } \\
\text { (median, copies/ ml) }\end{array}$ & range & \multicolumn{2}{l}{$\begin{array}{l}\text { PMN-MDSC frequencies } \\
\text { (median, \%) }\end{array}$} \\
\hline PR $(n=10)$ & 80 & $4-355$ & 276,802 & $2100-5,999,674$ & 2.37 & $0.23-14.41$ \\
$\mathrm{CO}(\mathrm{n}=5)$ & 923 & $644-1085$ & 40 & $<40-1940$ & 0.13 & $0.09-0.44$ \\
$\mathrm{BRO}(\mathrm{n}=6)$ & n.s. & n.s. & n.a. & n.a. & 2.84 & $1.62-6.76$ \\
$\mathrm{HC}(\mathrm{n}=5)$ & n.s. & n.s. & n.a. & n.a. & 0.48 & $0.11-1.85$ \\
\hline
\end{tabular}

$P R$ progressors, $C O$ controllers, $B R O$ patients with advanced-stage non-small cell lung carcinoma (NSCLC): disease stage III and IV; $H C$ healthy controls, $n . s$. not specified, n.a. not applicable.

determined on fresh PBMCs directly $(\leq 2 \mathrm{~h}$ after blood draw). For isolation of $\mathrm{CD} 66 \mathrm{~b}^{+}$cells, PBMCs were purified by positive selection of CD66b cells using magnetic microbeads (EasySep human whole blood CD66b positive selection kit, StemCell Technologies, France) according to the manufacturer's instructions. To increase purity, preselected $\mathrm{CD} 66 \mathrm{~b}^{+}$cells were flow-sorted gating on $\mathrm{CD} 6 \mathrm{~b}^{+} / \mathrm{CD} 15^{+}$on a FACS Aria (Becton Dickinson $\mathrm{GmbH}$, Heidelberg) for HIV-uninfected cells (BRO, HC) and on a MoFlo Astrios EQ (Beckman Coulter Life Sciences, Indianapolis, IN, USA) for HIV-infected samples (PR, CO). This procedure revealed high purities of PMN-MDSCs (median 89\%), even in the presence of extremely low PMN-MDSC frequencies among PMBCs. PMN-MDSC-depleted PBMCs (hereafter called "PBMCs depleted") contained a median of $0.08 \% \mathrm{CD} 6 \mathrm{~b}^{+}$cells.

\section{CD8 $\mathrm{T}$ cell proliferation assay}

CD8 $\mathrm{T}$ cell proliferation was evaluated by CFSE staining (5,6-carboxyfluorescein diacetate, succinimidyl ester, Sigma Aldrich, Germany) as described previously [36]. Briefly, PBMCs of HIV-uninfected target cells were labeled with CFSE and coincubated with either unstained target cells (negative and positive control) or with effector cells of study subjects $\left(\mathrm{CD}^{+} 6^{+}\right.$cells (PMNMDSCs) and CD66-depleted PBMCs (PBMCs depleted), respectively). The ratio of effector to target cells was 2:1. For nonspecific stimulation of all cells (except cells of negative control), PHA (phytohemagglutinin, $1.25 \mu \mathrm{g} / \mathrm{ml}$, Sigma Aldrich, Germany) was used. The negative control consisted of unstimulated cells. After culturing at $37^{\circ} \mathrm{C}$ and $5 \% \mathrm{CO}_{2}$ for $72 \mathrm{~h}$, target cells were stained extracellularly with CD8-PerCP (Biolegend) and analyzed on a FACSCalibur (BD, Germany) to determine CD8 T cell proliferation (for gating strategy see Additional file 1).

We defined the suppressive capacity as a readout for the functionality of MDSCs and used the following formula: $\frac{\text { Proliferation PMN-MDSCs-Proliferation"PBMCs depleted" }}{\text { Proliferation" PBMCs depleted" }} * 100$. A negative value for the suppressive capacity demonstrates the ability of PMN-MDSCs to inhibit CD8 $\mathrm{T}$ cell proliferation.

\section{Peptides}

Two pools of overlapping synthetic peptides corresponding to the HIV proteins Gag and Nef/Rev/Tat were used for HIV-specific stimulation (final concentration $2 \mu \mathrm{g} / \mathrm{ml}$ per peptide). Peptides were 15-20 amino acids long with an overlap of 5-10 amino acids, corresponding to Gag HIV-1 SF-2, to Nef HIV-1 18 BRU, to Tat HIV-1 LAI and to Rev. HIV-1 LAI, and had a purity of $\geq 70 \%$ (NIBSC, England).

\section{Phenotyping and flow cytometric analysis}

Extracellular staining of fresh PBMCs with fluorescent antibodies was performed as described previously [8] to determine the frequencies of PMN-MDSCs. For analysis of immune activation, immune exhaustion and polyfunctions of CD8 $\mathrm{T}$ cells, frozen PBMCs were thawed, cultured at $37{ }^{\circ} \mathrm{C}$ and $5 \% \mathrm{CO}_{2}$ overnight and phenotyped in two panels. For panel 1 (immune activation, immune exhaustion), cells were extracellularly stained [8]. For panel 2, cells were stimulated with either Gag or Nef/Rev/Tat peptides or left unstimulated (negative control) in three tubes. CD107aFITC was directly added to each of the tubes, which were cultured for $1 \mathrm{~h}$ at $37{ }^{\circ} \mathrm{C}$ and $5 \% \mathrm{CO}_{2}$, after which monensin $\left(0.7 \mu \mathrm{l} / 10^{6}\right.$ cells, BD, Germany) and brefeldin $(10 \mu \mathrm{g} / \mathrm{ml}$, Sigma Aldrich, Germany) were added. After a total of $6 \mathrm{~h}$ of incubation, the cells were extracellularly and intracellularly stained for polyfunctions of CD8 $\mathrm{T}$ cells (according to [37, 38], for gating strategy see Additional file 1).

The following antibodies were used: PMN-MDSCs: CD11b-FITC, CD14-APC, CD15-PerCP/CD15-FITC, CD66b-PE [39, 40]; immune activation/immune exhaustion: CD8-Pacific blue, CD38-PE, HLA-DR-APC, PD-1-FITC, LAG-3-PE/Cy7; and polyfunctionality: CD8-Pacific blue, interferon-gamma-APC, IL-2-PE, TNF alpha-PE/Cy7 and CD107a-FITC (all BioLegend, USA, with the exception of CD107a-FITC: Becton Dickinson GmbH, Germany).

PMN-MDSCs were analyzed on a FACSCalibur (BD, Germany), and CD8 $\mathrm{T}$ cell surface markers with the exception of proliferation were analyzed on a FACSCanto II (BD, Germany). The analysis of data 
was performed using FlowJo software 10.2 (TreeStar, Inc. Ashland, OR, USA). The gating strategies of PMN-MDSCs are described in Fig. 1e. For the statistics, we indicated PMN-MDSCs as a percentage of PBMCs in all subgroups because the numbers of monocytes varied substantially in subjects with chronic viral infections.

\section{Cytokine staining}

IL-6 was determined by electrochemiluminescence immunoassay on a Cobas e411 (Roche, Mannheim, Germany). For cystatin C and CRP analyses, particleenhanced turbidimetric immunoassays (PETIA) were performed on a Cobas 8000 c702 and on a Cobas c311, respectively (both Roche, Mannheim, Germany). IL-8 and soluble CD14 (sCD14) were analyzed using a human IL-8/CXCL8 Quantikine ELISA Kit (D8000C) and a human CD14 Quantikine ELISA Kit (DC140) (both R\&D Systems, Inc. USA) following the manufacturer's instructions.

\section{Statistical analysis}

The statistical analyses were performed using GraphPad Prism version 5.0. In most cases, our data were not normally distributed. Therefore, we only used nonparametric tests. Comparisons between two groups were performed with the Mann-Whitney $U$ test (level of significance $p<0.05$ ), and comparisons between more than two groups were first tested with the Kruskal-Wallis test. If this was significant $(p<$ 0.05), we also performed pairwise Mann-Whitney U tests with Bonferroni-Correction for multiple testing. Three pairwise comparisons were considered relevant and were tested for each experiment as follows: PR vs. $\mathrm{CO}, \mathrm{PR}$ vs. $\mathrm{HC}$, and $\mathrm{PR}$ vs. BRO. The corrected level of significance, therefore, was $p<0.0167$. In Fig. 2e, the relevant two pairwise comparisons were $<$ 2.5 $\mathrm{PR}$ vs $>2.5 \mathrm{PR}$ and $<2.5 \mathrm{CO}$ vs $<2.5 \mathrm{PR}$ with a corrected level of significance of $p<0.025$. Only tests with significant results are indicated in the figures. The Spearman rank test was used for correlation analyses, and the Wilcoxon signed rank test was used for paired comparisons (level of significance $p<0.05$ ).

\section{Results}

The inhibitory potential of PMN-MDSCs varies widely in patients with chronic HIV infection

As previously described [8], we found significantly increased PMN-MDSC frequencies in PR versus CO $(p=$ 0.0013), whereas the frequencies in PR were comparable to those in BRO ( $p=0.87)$ (Fig. 1a, e). Next, we evaluated the functionality of the PMN-MDSCs. Again, analogous to published data, we determined that CD8 $\mathrm{T}$ cell proliferation was significantly inhibited by PMN-MDSCs within all patients $(p=0.0001)$ as well as within PR patients $(p=0.0039)$ (Fig. 1b and c).

The suppressive capacity of all groups was similar ( $p=0.27$, data not shown). However, we found that the extent of the inhibition in PR patients was widespread. The coincubation assay with PMN-MDSCs from the PR patient with the lowest PMN-MDSC frequency of $0.23 \%$ showed a strong inhibition of proliferation of CD8 T cells by PMN-MDSCs (proliferation with PBMCs depleted $65.90 \%$ vs. proliferation with PMN-MDSCs $26.60 \%$, Fig. 1d). Surprisingly, in another patient with a PMN-MDSC frequency of $8.05 \%$ (Fig. 1e), the proliferation of CD8 T cells was only slightly suppressed in the presence of PMN-MDSCs compared to proliferation with depleted PBMCs $(52.84 \%$ vs. $55.48 \%$ proliferating CD8 $\mathrm{T}$ cells) (Fig. 1f). This finding was confirmed by repeating the experiment several times.

The proliferation of CD8 $\mathrm{T}$ cells was significantly inhibited by PMN-MDSCs in all patients, especially the PR group. Interestingly, the ability of PMN-MDSCs to inhibit proliferation varied substantially between PR patients.

\section{Inverse correlation of suppressive capacity of PMN- MDSCs with their respective frequencies}

To further evaluate the extent of the inhibitory function of PMN-MDSCs, we determined the suppressive capacity in our cohort. Our previous observation was confirmed in that we found a highly significant correlation between the suppressive ca-pac-i-ty and PMNMDSC frequencies in individual patients (Fig. 2a; rho $=0.51, p=0.0082$ ). However, this correlation was to the effect that the higher the PMN-MDSC level was, the weaker the inhibitory potential. This could be shown for the entire cohort (Fig. 2a) as well as for the PR group (Fig. $2 \mathrm{~b}$ ) and the combined subgroup of PR and BRO (Additional file 2). In contrast, the correlation of suppressive capacity and PMN-MDSC frequencies was not significant in $\mathrm{CO}$ (Fig. 2c). Dividing the patients into those with low PMN-MDSC levels $(<2.5 \%$ of PBMCs) and those with high PMNMDSC frequencies ( $>2.5 \%$ of PBMCs), revealed that there was a significant difference in suppressive capacity for the entire cohort (Fig. 2d; $p=0.021$ ) and for the selective PR group (Fig. 2e; $p=0.016$ ). The cut-off value of $2.5 \%$ was chosen because this was the median PMN-MDSC frequency in the group of PR.

In conclusion, we found that the higher the PMNMDSC level in a patient is, the lower the suppressive capacity of this immunoinhibitory cell type. Taken together, these findings suggest a state of immune exhaustion in progressive HIV infection - the disease stage with the highest PMN-MDSC frequencies. 

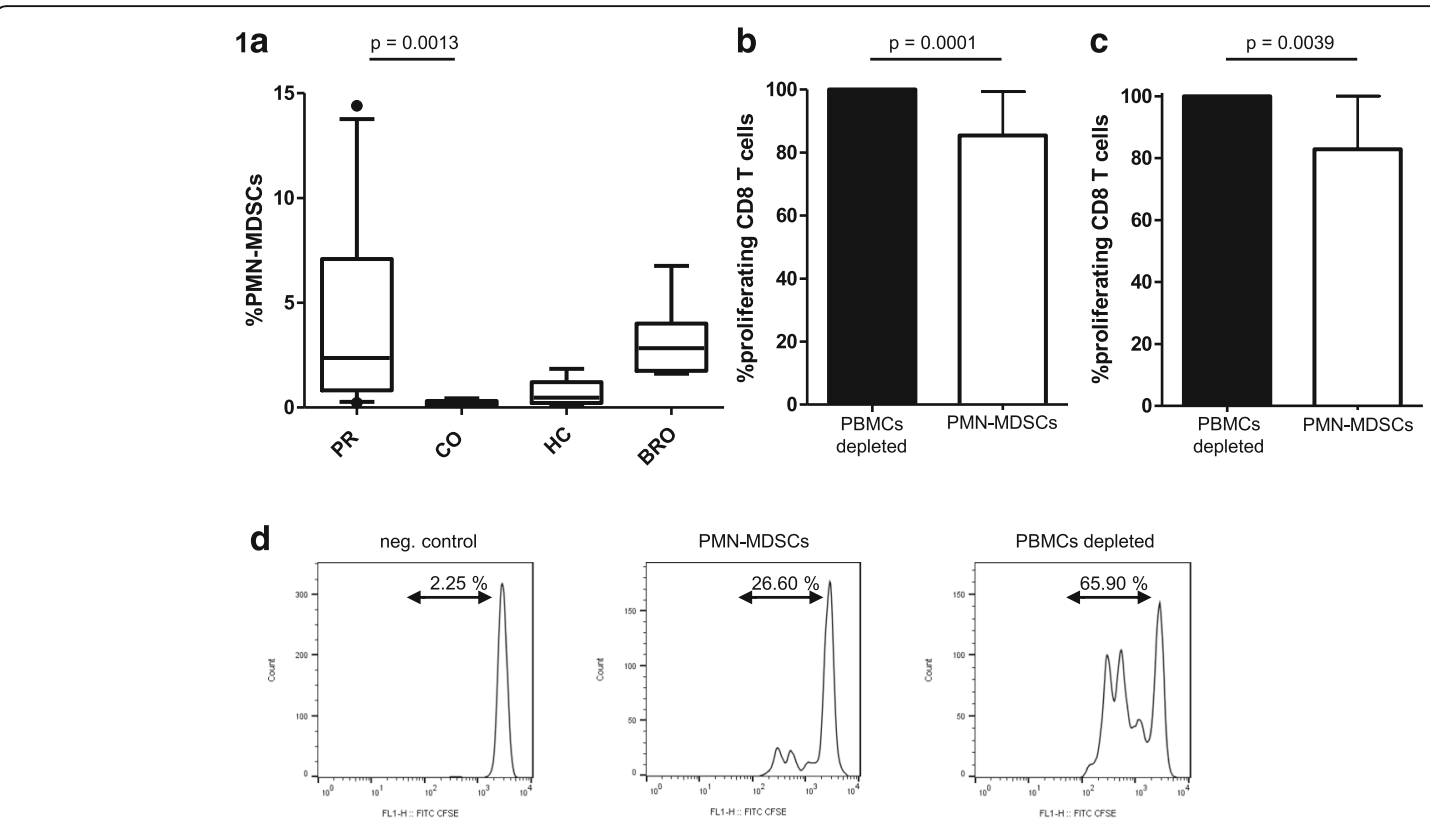

e
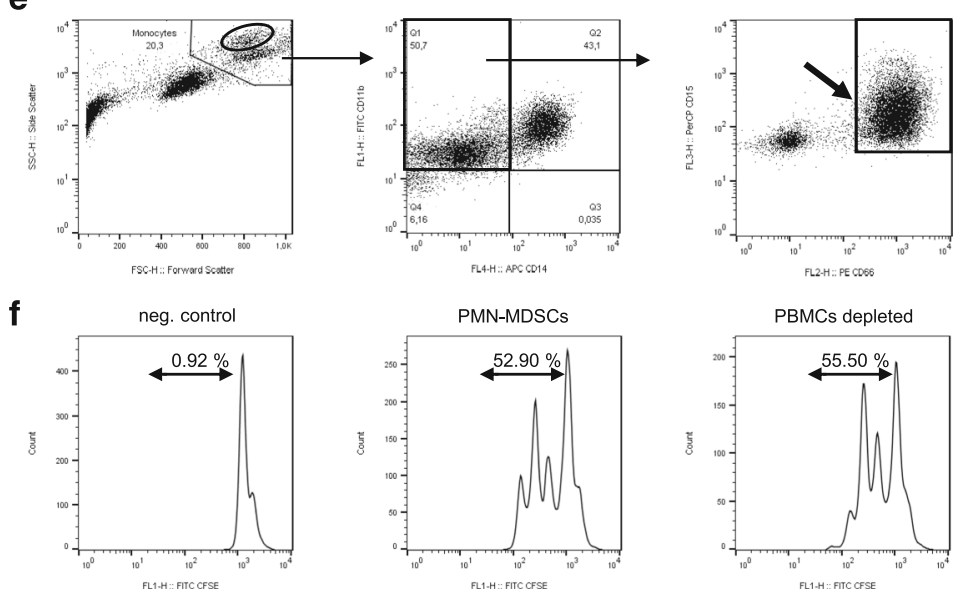

Fig. 1 Frequencies, suppressive function and gating strategy of PMN-MDSCs. a Progressors (PR) showed significantly higher PMN-MDSC frequencies than controllers (CO) $(p=0.0013)$, but there was no difference in the frequencies between PR patients and patients with lung carcinoma (BRO) $(p=0.87)$. ( $(\mathbf{b}+\mathbf{c})$ Significantly decreased percentages of proliferating CD8 T cells after coincubation with PMN-MDSCs compared to coincubation with PBMCs depleted in all patients $(p=0.0001)(\mathbf{b})$ and in PR $(p=0.0039)(\mathbf{c})$. The PBMCs depleted was set as $100 \%$, and PMNMDSCs were calculated as percentages thereof. $\mathbf{d}$ Histograms of a proliferation assay with significant inhibition of CD8 T cell proliferation by PMN-MDSCs in a sample from a patient with a low level of PMN-MDSCs (0.23\%). e Representative dot plots and gating of PMN-MDSCs. Gating here is demonstrated by a patient with a very high frequency of PMN-MDSCs (CD66 ${ }^{+}$CD15 $5^{+}$cells: 8.05\%). The first gate (first panel) is placed on the monocyte fraction in FSC and SSC. The main MDSC fraction is found in the population above the monocyte fraction (oval gate, first panel). The second panel shows the CD11 $\mathrm{b}^{+}$and $\mathrm{CD} 14^{-}$populations (upper left gate). PMN-MDSCs are defined as CD $11 \mathrm{~b}^{+}$CD $14^{-}$CD $66 \mathrm{~b}^{+} \mathrm{CD} 15^{+}$and are shown in the upper right gate of the third panel. Gating was performed according to Vollbrecht et al. [8] and Rieber et al. [37, 38]. f Histograms of a proliferation assay with only minimal inhibition by PMN-MDSCs from the patient shown in (e). [PR: $n=10 ; C O: n=5 ; H C: n=5$; BRO: $n=6]$

No correlation between the suppressive capacity of PMNMDSCs and the polyfunctionality of CD8 T cells or immunoinhibitory signals

In HIV infection, immune exhaustion of CD8 T cells is well described and reflected in the reduction of effector functions. We wanted to determine whether the suppressive capacity of PMN-MDSCs is related to the polyfunctionality of CD8 $\mathrm{T}$ cells. As PMNMDSCs are inhibitors of CD8 T cells, a strong inhibitory potential might be correlated with more monofunctional CD8 T cells. For this purpose, we stained for the four CD8 $\mathrm{T}$ cell effector functions interferon-gamma, TNF alpha, IL-2 and CD107a as a marker for degranulation after specific stimulation 

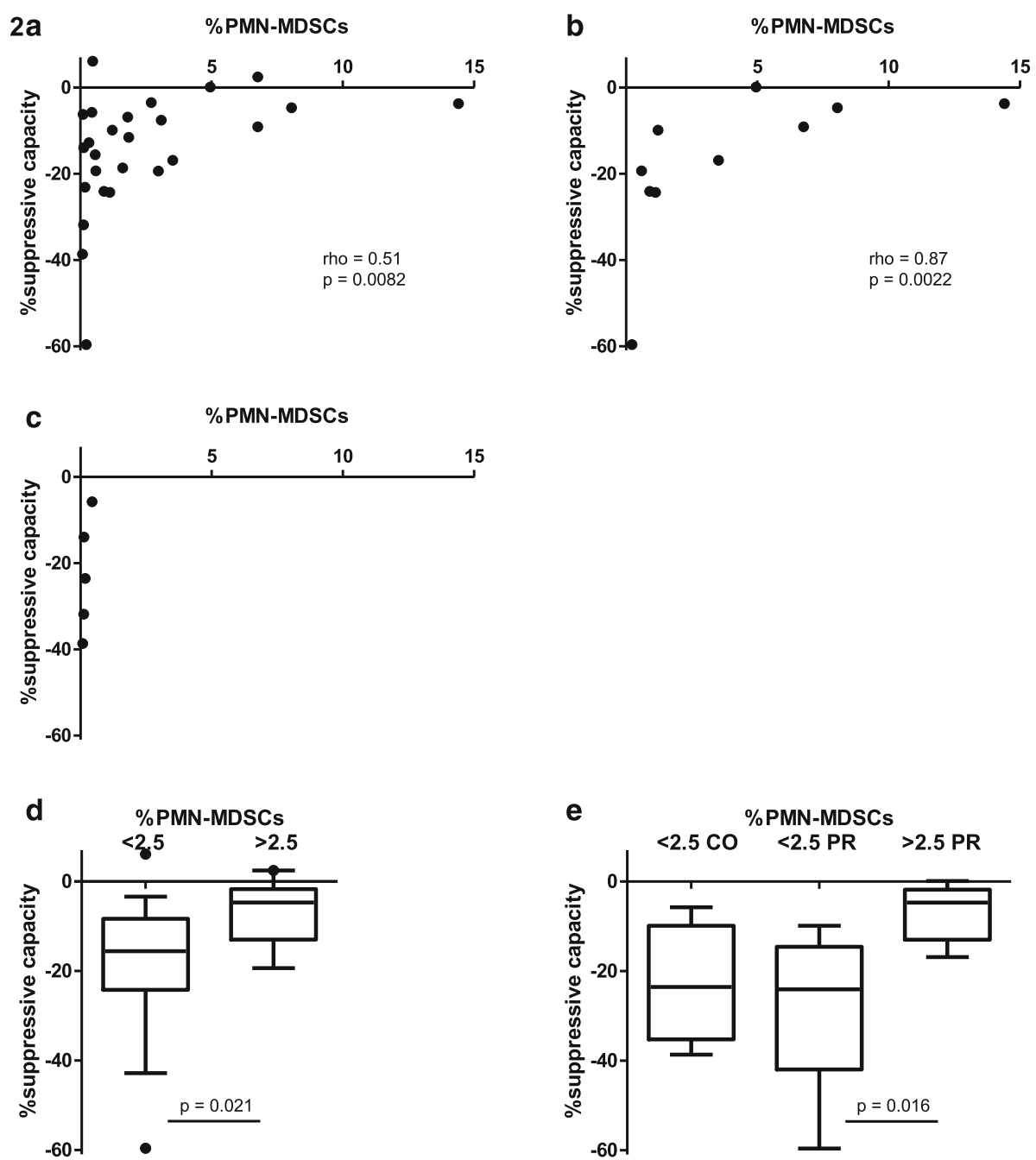

Fig. 2 Suppressive capacity of PMN-MDSCs and correlation with PMN-MDSC frequencies. $(\mathbf{a}+\mathbf{b}+\mathbf{c})$ The suppressive capacity of PMN-MDSCS correlates inversely and significantly with the PMN-MDSC frequencies in all subjects (rho $=0.51, p=0.0082)(\mathbf{a})$ and in progressors (PR) (rho $=0.87$, $p=0.0022)(\mathbf{b})$, whereas there is no significant correlation in controllers (CO) (rho $=0.90, p=0.083)(\mathbf{c})$. ( $\mathbf{d}+\mathbf{e})$ The suppressive capacity is significantly lower in subjects with PMN-MDSC frequencies above $2.5 \%$ compared to subjects with frequencies below $2.5 \%$ in all subjects ( $p=$ $0.021)$ (d) and in PR subjects ( $p=0.016)(\mathbf{e})$. All controllers have PMN-MDSC frequencies below 2.5\% (e). [all subjects: $n=26 ;$ PR: $n=10 ; C O: n=5$; $H C: n=5 ; B R O: n=6]$

with HIV peptides. We found no correlation in either direction between the effector functions of HIVspecific CD8 $\mathrm{T}$ cells and the suppressive capacity of PMN-MDSCs (data not shown).

Next, we evaluated whether there is an association between immunoinhibitory signals and the inhibitory potential of PMN-MDSCs and chose PD-1 and LAG-3 for this purpose. As PMN-MDSCs have been shown to use the PD-1/PD-L1 pathway, a strong suppressive capacity of PMN-MDSCs could be related to high levels of immune checkpoint molecules. There was, however, no significant correlation between PD-1 or LAG-3 levels on CD8 $\mathrm{T}$ cells with either the frequency of PMN-MDSCs or the suppressive capacity of PMN-MDSCs in our cohort (data not shown).
Correlation of the suppressive capacity of PMN-MDSCs with the proinflammatory cytokine IL-8

The immune exhaustion of certain cell types in progressive HIV infection is associated with the well-described hyperactive immune state. We hypothesized that the loss of effector functions of PMN-MDSCs is also correlated with this immune activation. Therefore, we determined the CD38 and HLA-DR expression levels on CD8 T cells as well as levels of markers of inflammation in plasma, namely, cystatin c, highly sensitive CRP, IL-6, IL-8 and sCD14.

As expected, the PR group exhibited significantly higher proportions of $\mathrm{CD}^{+} 8^{+}$and HLA-DR ${ }^{+} \mathrm{CD} 8 \mathrm{~T}$ cells compared to the $\mathrm{CO}$ and $\mathrm{HC}$ groups (Fig. 3a; $p=0.0031$ and $p=0.0016$, respectively). However, there was no 

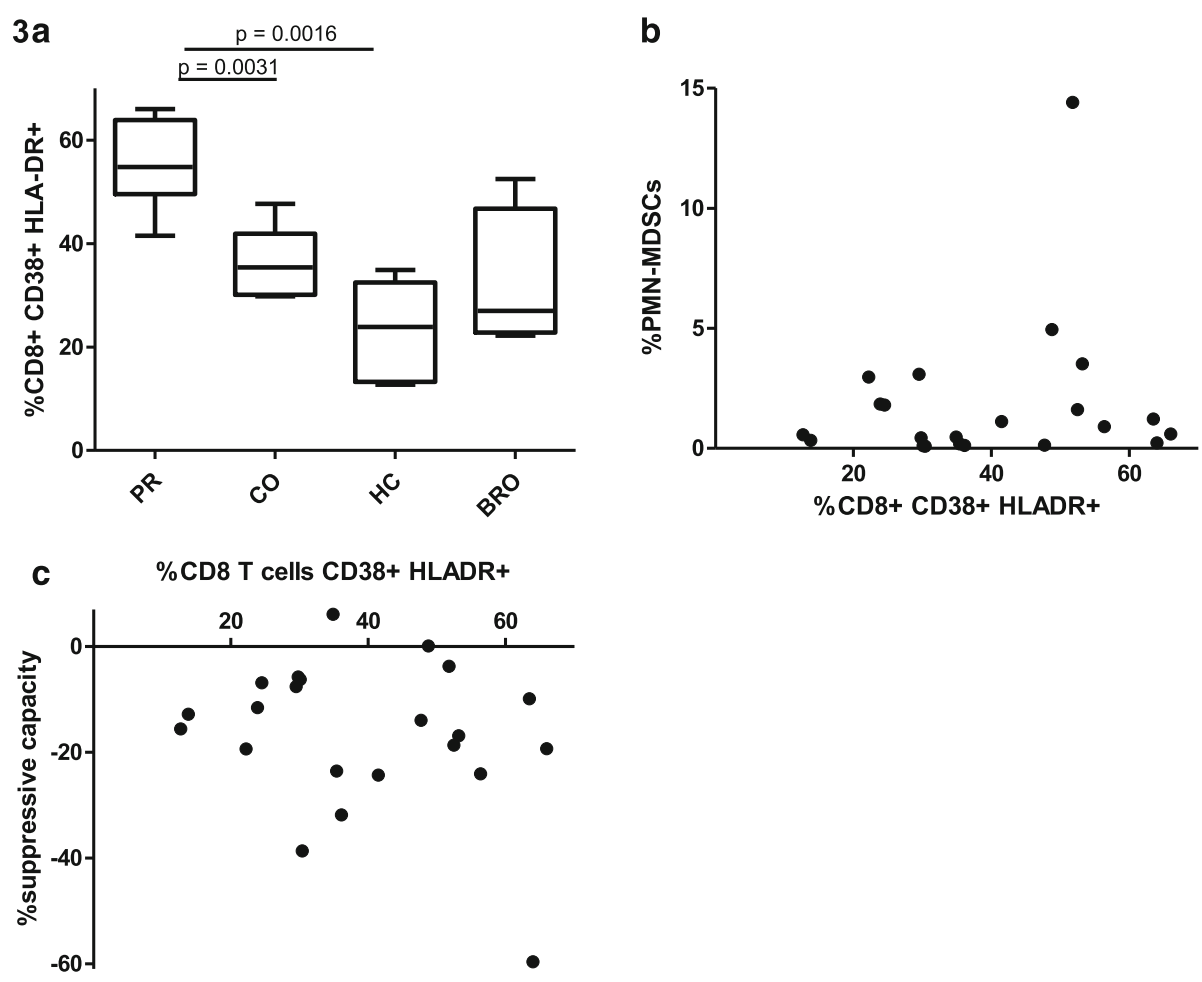

d

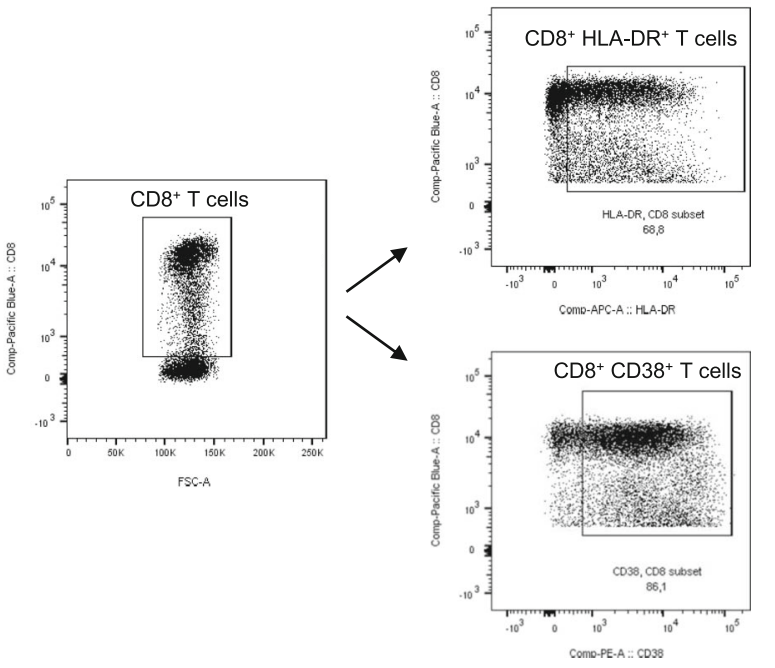

Fig. 3 Immune activation and correlation of $\mathrm{CD}^{+} \mathrm{CD} 38^{+} \mathrm{HLA}-\mathrm{DR}{ }^{+}$cells with frequencies and suppressive capacity of PMN-MDSCs. a Frequencies of CD8 T cells expressing CD38 and HLA-DR were significantly higher in progressors (PR) than in controllers (CO) $(p=0.0031)$ and healthy controls $(p=0.0016)$. $\mathbf{b}$ CD8 T cells expressing CD38 and HLA-DR do not correlate with PMN-MDSC frequencies (rho $=0.085, p=0.71)(\mathbf{b})$ and suppressive capacity (rho $=-0.25, p=0.27$ ) (c) in all subjects. $\mathbf{d}$ Representative dot plots and gating strategies of activated CD8 T cells. The first panel shows the lymphocyte population. The CD8 positive cells are gated in the second panel (rectangular gate). Afterwards, CD8 T cells were gated on the markers HLA-DR and CD38. [all subjects: $n=22 ;$ PR: $n=8$; CO: $\mathrm{n}=5$; HC: $\mathrm{n}=5$; BRO: $n=4$ ]

correlation between the $\mathrm{CD}^{+} 8^{+}$and $\mathrm{HLA}^{-\mathrm{DR}}{ }^{+} \mathrm{CD} 8 \mathrm{~T}$ cells and either the PMN-MDSC frequencies or the suppressive capacity (Fig. $3 \mathrm{~b}$ and c). The same was true for cystatin C, highly sensitive CRP, IL-6 and sCD14 (data not shown).

For plasma IL-8 levels, the Kruskal-Wallis test for the comparison of more than two groups reached significance $(p=0.037)$ which was driven by the high IL- 8 levels in the BRO group. However, plasma IL-8 levels failed to reach statistical significance in the pairwise comparison between PR vs. $\mathrm{CO}, \mathrm{HC}$ or $\mathrm{BRO}(p>0.098)$ (Fig. 4a). Interestingly, we found a significant correlation between IL-8 levels and PMN-MDSC frequencies and suppressive capacity (Fig. 4b: rho $=0.52, p=0.0074$ and Fig. 4c: rho $=0.47, p=0.019)$. 

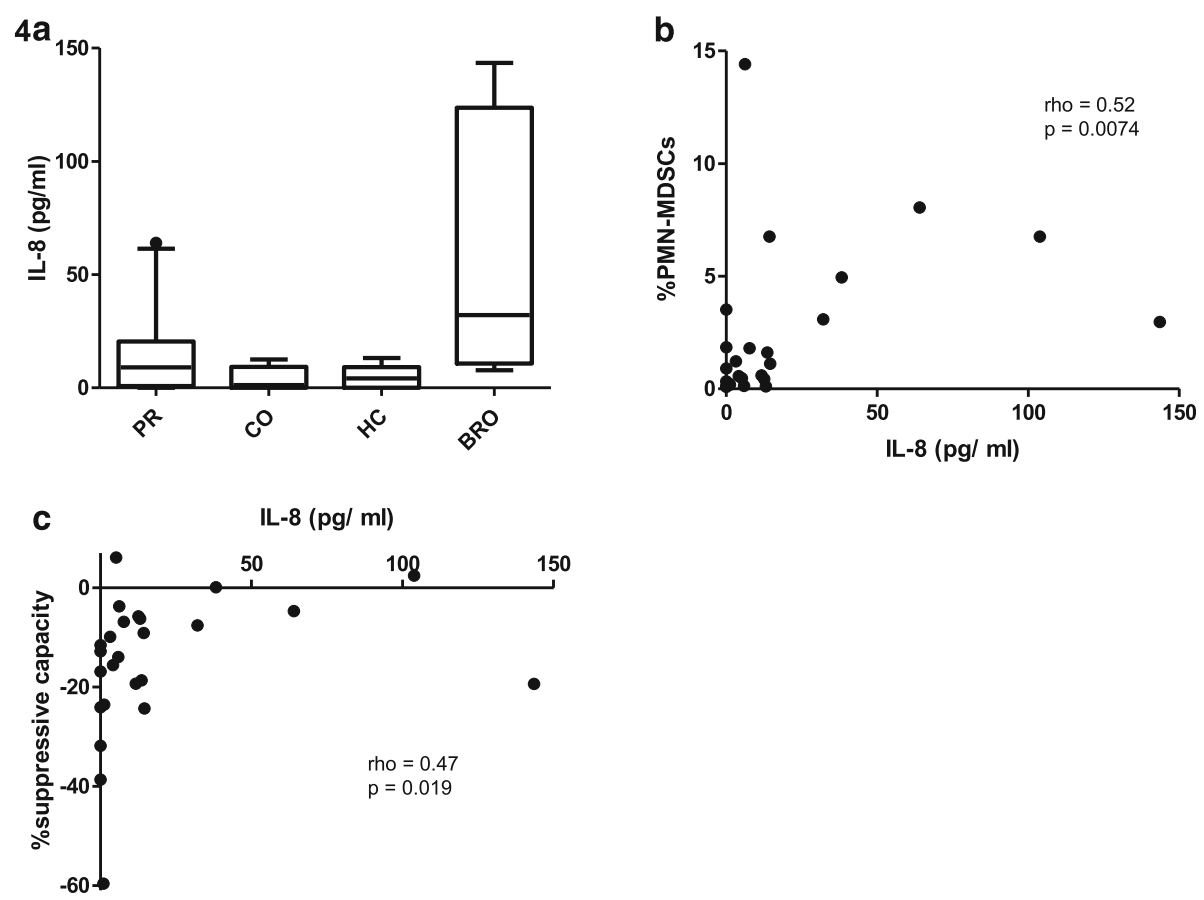

Fig. 4 Plasma levels of IL-8 and their correlation with the frequencies and suppressive capacity of PMN-MDSCs. a Plasma IL-8 levels were comparable in progressors (PR), controllers (CO), healthy controls $(\mathrm{HC})$ and patients with lung cancer (BRO) $(p>0.098)$; however, the Kruskal-Wallis test for the comparisons of more than two groups reached significance $(p=0.037)$. b IL-8 levels correlated directly and significantly with frequencies (rho $=0.52, p=0.0074)(\mathbf{b})$ and suppressive capacity (rho $=0.47, p=0.019)$ (c) of PMN-MDSCs in all subjects. [PR: $n=10, C O: n=5, H C$ : $\mathrm{n}=5$, BRO: $\mathrm{n}=5$, all subjects: $n=25]$

The higher the IL-8 levels in a patient are, the weaker the PMN-MDSCs' suppressive capacity.

In conclusion, the loss of the inhibitory potential of PMN-MDSCs is associated with an increase in the levels of the proinflammatory cytokine IL-8, which is an important cytokine for the migration and adhesion of polymorphonuclear cells.

\section{Discussion}

To the best of our knowledge, in this study, we describe for the first time that PMN-MDSCs become exhausted in advanced HIV disease. Our data show a diminished suppressive capacity of these cells in patients with far advanced disease status and a high frequency of PMNMDSCs. This limitation of suppressive capacity was not correlated with markers of immunoinhibition (e.g., PD1) but to immune activation, namely, the proinflammatory cytokine IL-8.

Inhibition of CD8 T cell function by PMN-MDSCs is well described to occur not only with malignant diseases but also in HIV infection [2, 4-6, 8, 9, 41-43]. In our cohort, we observed significant inhibition of CD8 T cell proliferation by purified PMN-MDSCs, and thus we confirmed data previously published by our group and by others $[8,43]$. Interestingly, we found differences in PR patients regarding the potential to suppress $\mathrm{T}$ cell function. First, one AIDS patient with an exceptionally high PMN-MDSC frequency showed an almost complete lack of inhibition of $\mathrm{T}$ cell proliferation in repeated experiments. Testing a cohort of patients with advanced disease, we confirmed the results that the inhibitory effect of PMN-MDSCs declined with increasing PMNMDSC frequencies. This finding was not only true for chronic HIV infection but also for late-stage lung cancer, as shown in our group of patients with bronchial carcinoma, which we used as positive controls (see Additional file 2). Thus far, the exhaustion of PMNMDSCs in the disease course has not been described for either the cancer setting or chronic viral infections.

Immune exhaustion during progressive disease, however, is a well-known fact in HIV-specific CD8 T cells [14, 44-47]. In a typical succession, these cells lose effector functions, starting with the loss of the capability to produce IL-2 and TNF alpha. Interferon-gamma production is one of the last remaining functions $[14,45$, $48,49]$. The progressive exhaustion of CD8 $\mathrm{T}$ cells (among other immune cells) results in an increased viral load and disease progression in chronic, untreated HIV infection [14]. In addition to CD8 T cells, the exhaustion of other immune cells such as CD4 T cells, B cells and NK cells has been reported in progressive HIV infection $[15-19,22,49]$. Therefore, the principle of immune 
exhaustion seems to hold true for a wide range of immune cells - now also including PMN-MDSCs.

We further wanted to test whether the differing suppressive capacity of PMN-MDSCs has varying influences on $\mathrm{T}$ cell effector functions. If so, a strong suppressive capacity would be found in patients without diverse CD8 $\mathrm{T}$ cell cytokine production. However, we were not able to demonstrate such a relationship in our experimental setting. There also does not seem to be any evidence in the literature showing such an association. Exhausted $\mathrm{T}$ cells in HIV infection express elevated markers of immunoinhibition, e.g., PD-1 or LAG-3 [20, 50-56]. It is accepted that the loss of $\mathrm{T}$ cell function is induced by these inhibitory pathways, which is why they are also called immune checkpoint molecules [16, 50-52]. There is evidence that MDSCs use the PD-1/PD-L1 pathway for their suppressive function with regard to $\mathrm{T}$ cell proliferation [57, 58]. Therefore, we hypothesized that a strong suppressive capacity of PMN-MDSCs involves high PD-1 expression on T cells. In our study, we were not able to prove the hypothesis of a correlation between the suppressive capacity of PMN-MDSCs and the level of these well-described markers of immune exhaustion on $\mathrm{T}$ cells.

However, the level and functionality of PMN-MDSCs were distinctly associated with immune activation. Notably, we observed a correlation between the frequency and suppressive capacity of PMN-MDSCs and plasma levels of the proinflammatory cytokine IL-8. Increased IL-8 levels were related to increased PMN-MDSC frequencies and reduced suppressive capacity. Hence, excessive immune activation in progressive HIV infection is also associated with decreased PMN-MDSC function.

In our study, there was no correlation between the suppressive capacity of PMN-MDSCs and the expression of CD38 and/or HLA-DR on T cells. However, CD38 and HLA-DR are activation markers of the T lymphocyte pathway. PMN-MDSCs, on the other hand, are closely related to granulocytes, which are part of a different developmental strand. IL-8 is an important cytokine for this cell type. The CXC chemokine IL-8 attracts neutrophils to sites of inflammation [28, 59-62]. More recently, it was reported that IL-8 also attracts MDSCs (PMN-MDSCs as well as M-MDSCs) isolated from cancer patients in transwell migration assays. The authors showed the expression of the IL-8 receptors CXCR1 and CXCR2 on the surface of PMN-MDSCs [63]. Interestingly, we were also able to observe significantly higher expression levels of CXCR1 and CXCR2 on PMN-MDSCs in PR compared to healthy controls (preliminary unpublished data of our group).

Increased IL-8 plasma levels in cancer patients predict increased disease severity [64-67]. Consistently, published data in HIV infection has shown that increased IL-8 levels correlate with mortality, reduced CD4 cell count and increased viral load [28-33]. In a study of HIV/tuberculosis coinfected patients, a direct association of plasma IL-8 levels was found with frequencies of granulocytes and their capacity to migrate in response to IL-8. Moreover, markedly increased IL-8 levels were observed in lymphoid tissue in patients with progressive HIV infection [27].

Based on the above-mentioned data in cancer and HIV, it is tempting to suggest that in progressive HIV infection, PMN-MDSCs migrate to major sites of HIV replication, namely, the lymphoid tissue, induced by elevated levels of IL-8. As PMN-MDSCs are nonfunctional in advanced disease, increased levels of IL-8 should attract more PMN-MDSCs. However, our data reflect the levels of IL-8 and MDSCs in human blood only and are limited with regard to lymphatic tissue. The latter remains to be elucidated in future studies.

In conclusion, our study is the first to show a limitation of functionality of PMN-MDSCs in advanced HIV disease. Our results support a close relationship between this limitation of suppressive capacity of MDSCs and immune activation. Hence, the results of this study unravel another component of HIV immunopathogenesis.

\section{Supplementary information}

Supplementary information accompanies this paper at https://doi.org/10. 1186/s41231-019-0052-5.

Additional file 1: Figure S1. Gating strategies for proliferation and polyfunctions of CD8 T cells.

Additional file 2: Figure S2. Suppressive capacity of PMN-MDSCs and correlation with PMN-MDSC frequencies for the combined subgroup PR and $\mathrm{BRO}$.

\section{Abbreviations}

BRO: Patients with advanced-stage non-small cell lung carcinoma; CO: Controllers; EC: Elite controllers; HC: HIV-uninfected/healthy controls; MDSCs: Myeloid-derived suppressor cells; M-MDSCs: Monocytic myeloidderived suppressor cells; NSCLC: Non small cell lung cancer; PBMC: Peripheral blood mononuclear cells; PETIA: Particle-enhanced turbidimetric

immunoassays; PMN-MDSCs: Polymorphonuclear myeloid-derived suppressor cells; PR: Progressors; sCD14: Soluble CD14; VL: Viral load

\section{Acknowledgements}

We thank all the study participants for their participation and blood donation. In addition, we thank our clinical colleagues at the hospital who collected the study materials.

\section{Authors' contributions}

EMG identified eligible patients, acquired data, performed research, analyzed data, performed statistical analysis and drafted the manuscript. AN identified eligible patients, acquired data, performed research, analyzed data, performed statistical analysis. RS acquired data and performed research. RC, IA, LW, MS, LMH, CK gave advice on cell sorting, contributed materials, reagents and analysis tools. JRB interpreted data, wrote manuscript. RD designed research, analyzed and interpreted data, performed statistical analysis, wrote manuscript and revised final version of the manuscript. All authors read, commented and approved the final manuscript.

\section{Funding}

This work was supported by the Deutsche Zentrum für Infektionsforschung (DZIF) TTU HIV site Munich LMU (project number TTU 04.811 to RD) and the 
Else Kröner-Fresenius Stiftung (EKFS; 2014_A217 to RD). The funders had no role in the design of the study and collection, analysis, and interpretation of data, in the writing of the manuscript and in the decision to submit the work for publication.

\section{Availability of data and materials}

The datasets generated and analyzed during the current study are available from the corresponding author on reasonable request.

\section{Ethics approval and consent to participate}

The study was approved by the Institutional Review Board of the LudwigMaximilian-Universität, Munich, Germany (project number: 227-11). All participants signed informed consent.

\section{Consent for publication}

Not applicable.

\section{Competing interests}

The authors declare that they have no competing interests.

\section{Author details}

'Division of Infectious Diseases, Medizinische Klinik und Poliklinik IV, Ludwig Maximilian University Hospital of Munich, Pettenkoferstr. 8a, 80336 Munich, Germany. ${ }^{2}$ German Center for Infection Research (DZIF), Munich partner site, Munich, Germany. ${ }^{3}$ Dr. von Hauner Children's Hospital, University Hospital, Department of Pediatrics, Ludwig Maximilian University, Munich, Germany. ${ }^{4}$ Institut für Medizinische Mikrobiologie, Immunologie und Hygiene, Technische Universität, Munich, Germany. ${ }^{5}$ Institute of Virology, Technische Universität / Helmholtz Zentrum Munich, Munich, Germany. ${ }^{6}$ Institute of Laboratory Medicine, Ludwig Maximilian University Hospital of Munich, Munich, Germany.

\section{Received: 18 September 2019 Accepted: 30 December 2019}

\section{-. - 10 .}

\section{References}

1. Bronte V, Brandau S, Chen SH, Colombo MP, Frey AB, Greten TF, et al. Recommendations for myeloid-derived suppressor cell nomenclature and characterization standards. Nat Commun. 2016;7:12150.

2. Dumitru CA, Moses K, Trellakis S, Lang S, Brandau S. Neutrophils and granulocytic myeloid-derived suppressor cells: immunophenotyping, cell biology and clinical relevance in human oncology. Cancer Immunol Immunother. 2012;61(8):1155-67.

3. Greten TF, Manns MP, Korangy F. Myeloid derived suppressor cells in human diseases. Int Immunopharmacol. 2011;11(7):802-7.

4. Brandau S, Trellakis S, Bruderek K, Schmaltz D, Steller G, Elian M, et al. Myeloid-derived suppressor cells in the peripheral blood of cancer patients contain a subset of immature neutrophils with impaired migratory properties. J Leukoc Biol. 2011;89(2):311-7.

5. Trellakis S, Bruderek K, Hutte J, Elian M, Hoffmann TK, Lang S, et al. Granulocytic myeloid-derived suppressor cells are cryosensitive and their frequency does not correlate with serum concentrations of colony-stimulating factors in head and neck cancer. Innate Immun. 2013;19(3):328-36.

6. Hoechst B, Ormandy LA, Ballmaier M, Lehner F, Kruger C, Manns MP, et al. A new population of myeloid-derived suppressor cells in hepatocellular carcinoma patients induces CD4(+)CD25(+)Foxp3(+) T cells. Gastroenterology. 2008;135(1):234-43.

7. Rodriguez PC, Ernstoff MS, Hernandez C, Atkins M, Zabaleta J, Sierra R, et al. Arginase I-producing myeloid-derived suppressor cells in renal cell carcinoma are a subpopulation of activated granulocytes. Cancer Res. 2009; 69(4):1553-60

8. Vollbrecht T, Stirner R, Tufman A, Roider J, Huber RM, Bogner JR, et al. Chronic progressive HIV-1 infection is associated with elevated levels of myeloid-derived suppressor cells. AIDS. 2012;26(12):F31-7.

9. Tumino N, Turchi F, Meschi S, Lalle E, Bordoni V, Casetti R, et al. In HIVpositive patients, myeloid-derived suppressor cells induce T-cell anergy by suppressing CD3zeta expression through ELF-1 inhibition. AIDS. 2015;29(18):2397-407.
10. Yang Q, Qiu H, Xie H, Qi Y, Cha H, Qu J, et al. A Schistosoma japonicum infection promotes the expansion of myeloid-derived suppressor cells by activating the JAK/STAT3 pathway. J Immunol. 2017;198(12):4716-27.

11. Wang C, Zhang N, Qi L, Yuan J, Wang K, Wang K, et al. Myeloid-derived suppressor cells inhibit $\mathrm{T}$ follicular helper cell immune response in Japanese encephalitis virus infection. J Immunol. 2017;199(9):3094-105.

12. Dross SE, Munson PV, Kim SE, Bratt DL, Tunggal HC, Gervassi AL, et al. Kinetics of myeloid-derived suppressor cell frequency and function during simian immunodeficiency virus infection, combination antiretroviral therapy, and treatment interruption. J Immunol. 2017;198(2):757-66.

13. Grutzner EM, Hoffmann T, Wolf E, Gersbacher E, Neizert A, Stirner R, et al. Treatment intensification in HIV-infected patients is associated with reduced frequencies of regulatory T cells. Front Immunol. 2018;9:811.

14. Betts MR, Nason MC, West SM, De Rosa SC, Migueles SA, Abraham J, et al. HIV nonprogressors preferentially maintain highly functional HIV-specific CD8+ T cells. Blood. 2006;107(12):4781-9.

15. Kannanganat S, Kapogiannis BG, Ibegbu C, Chennareddi L, Goepfert P, Robinson $\mathrm{HL}$, et al. Human immunodeficiency virus type 1 controllers but not noncontrollers maintain CD4 T cells coexpressing three cytokines. J Virol. 2007;81(21):12071-6.

16. Porichis F, Kwon DS, Zupkosky J, Tighe DP, McMullen A, Brockman MA, et al. Responsiveness of HIV-specific CD4 T cells to PD-1 blockade. Blood. 2011;118(4): 965-74.

17. Kared H, Martelli S, Tan SW, Simoni Y, Chong ML, Yap SH, et al. Adaptive NKG2C(+)CD57(+) natural killer cell and Tim-3 expression during viral infections. Front Immunol. 2018:9:686.

18. Moir S, Fauci AS. B-cell exhaustion in HIV infection: the role of immune activation. Curr Opin HIV AIDS. 2014;9(5):472-7.

19. Moir S, Ho J, Malaspina A, Wang W, DiPoto AC, O'Shea MA, et al. Evidence for HIV-associated B cell exhaustion in a dysfunctional memory B cell compartment in HIV-infected viremic individuals. J Exp Med. 2008:205(8):1797-805.

20. Kaufmann DE, Kavanagh DG, Pereyra F, Zaunders JJ, Mackey EW, Miura T, et al. Upregulation of CTLA-4 by HIV-specific CD4+ T cells correlates with disease progression and defines a reversible immune dysfunction. Nat Immunol. 2007:8(11):1246-54.

21. D'Souza M, Fontenot AP, Mack DG, Lozupone C, Dillon S, Meditz A, et al. Programmed death 1 expression on HIV-specific CD4+ T cells is driven by viral replication and associated with T cell dysfunction. J Immunol. 2007;179(3):1979-87.

22. Porichis F, Hart MG, Massa A, Everett HL, Morou A, Richard J, et al. Immune checkpoint blockade restores HIV-specific CD4 T cell help for NK cells. J Immunol. 2018;201(3):971-81.

23. Liu Z, Cumberland WG, Hultin LE, Prince HE, Detels R, Giorgi JV. Elevated CD38 antigen expression on CD8+ T cells is a stronger marker for the risk of chronic HIV disease progression to AIDS and death in the multicenter AIDS cohort study than CD4+ cell count, soluble immune activation markers, or combinations of HLA-DR and CD38 expression. J Acquir Immune Defic Syndr Hum Retrovirol. 1997;16(2):83-92.

24. Giorgi JV, Hultin LE, McKeating JA, Johnson TD, Owens $B$, Jacobson LP, et al. Shorter survival in advanced human immunodeficiency virus type 1 infection is more closely associated with T lymphocyte activation than with plasma virus burden or virus chemokine coreceptor usage. J Infect Dis. 1999:179(4):859-70.

25. Deeks SG. HIV infection, inflammation, immunosenescence, and aging. Annu Rev Med. 2011;62:141-55.

26. Neuhaus J, Jacobs DR Jr, Baker JV, Calmy A, Duprez D, La Rosa A, et al. Markers of inflammation, coagulation, and renal function are elevated in adults with HIV infection. J Infect Dis. 2010;201(12):1788-95.

27. Meddows-Taylor S, Martin DJ, Tiemessen CT. Dysregulated production of interleukin-8 in individuals infected with human immunodeficiency virus type 1 and mycobacterium tuberculosis. Infect Immun. 1999;67(3):1251-60

28. Lane BR, Lore K, Bock PJ, Andersson J, Coffey MJ, Strieter RM, et al. Interleukin-8 stimulates human immunodeficiency virus type 1 replication and is a potential new target for antiretroviral therapy. J Virol. 2001;75(17):8195-202.

29. Ronsholt FF, Ullum H, Katzenstein TL, Gerstoft J, Ostrowski SR. Persistent inflammation and endothelial activation in HIV-1 infected patients after 12 years of antiretroviral therapy. PLoS One. 2013:8(6):e65182.

30. Jason J, Archibald LK, Nwanyanwu OC, Byrd MG, Kazembe PN, Dobbie H, et al. Comparison of serum and cell-specific cytokines in humans. Clin Diagn Lab Immunol. 2001;8(6):1097-103. 
31. Berg A, Patel S, Gonca M, David C, Otterdal K, Ueland T, et al. Cytokine network in adults with falciparum malaria and HIV-1: increased IL-8 and IP10 levels are associated with disease severity. PLoS One. 2014;9(12):e114480.

32. Pananghat AN, Aggarwal H, Prakash SS, Makhdoomi MA, Singh R, Lodha R, et al. IL-8 alterations in HIV-1 infected children with disease progression. Medicine (Baltimore). 2016;95(21):e3734.

33. French MA, Cozzi-Lepri A, Arduino RC, Johnson M, Achhra AC, Landay A, et al. Plasma levels of cytokines and chemokines and the risk of mortality in HIV-infected individuals: a case-control analysis nested in a large clinical trial. AIDS. 2015;29(7):847-51.

34. Mamik MK, Ghorpade A. Chemokine CXCL8 promotes HIV-1 replication in human monocyte-derived macrophages and primary microglia via nuclear factor-kappaB pathway. PLoS One. 2014;9(3):e92145.

35. Hess C, Means TK, Autissier P, Woodberry T, Altfeld M, Addo MM, et al. IL-8 responsiveness defines a subset of CD8 T cells poised to kill. Blood. 2004; 104(12):3463-71

36. Watson D, Zhang GY, Sartor M, Alexander SI. "pruning" of alloreactive CD4+ T cells using 5- (and 6-)carboxyfluorescein diacetate succinimidyl ester prolongs skin allograft survival. J Immunol. 2004;173(11):6574-82.

37. Betts MR, Brenchley JM, Price DA, De Rosa SC, Douek DC, Roederer M, et al. Sensitive and viable identification of antigen-specific CD8+ T cells by a flow cytometric assay for degranulation. J Immunol Methods. 2003;281(1-2):65-78

38. Alter G, Tsoukas CM, Rouleau D, Cote P, Routy JP, Sekaly RP, et al. Assessment of longitudinal changes in HIV-specific effector activity in subjects undergoing untreated primary HIV infection. AIDS. 2004;18(15): 1979-89.

39. Rieber N, Brand A, Hector A, Graepler-Mainka U, Ost M, Schafer I, et al. Flagellin induces myeloid-derived suppressor cells: implications for Pseudomonas aeruginosa infection in cystic fibrosis lung disease. J Immunol. 2013;190(3):1276-84.

40. Rieber N, Gille C, Kostlin N, Schafer I, Spring B, Ost M, et al. Neutrophilic myeloid-derived suppressor cells in cord blood modulate innate and adaptive immune responses. Clin Exp Immunol. 2013;174(1):45-52.

41. Qin A, Cai W, Pan T, Wu K, Yang Q, Wang N, et al. Expansion of monocytic myeloid-derived suppressor cells dampens T cell function in HIV-1seropositive individuals. J Virol. 2013;87(3):1477-90.

42. Bowers NL, Helton ES, Huijbregts RP, Goepfert PA, Heath SL, Hel Z. Immune suppression by neutrophils in HIV-1 infection: role of PD-L1/PD-1 pathway. PLoS Pathog. 2014;10(3):e1003993.

43. Tumino N, Bilotta MT, Pinnetti C, Ammassari A, Antinori A, Turchi F, et al. Granulocytic myeloid-derived suppressor cells increased in early phases of primary HIV infection depending on TRAIL plasma level. J Acquir Immune Defic Syndr. 2017;74(5):575-82.

44. Douek DC, Roederer M, Koup RA. Emerging concepts in the immunopathogenesis of AIDS. Annu Rev Med. 2009;60:471-84.

45. Wherry EJ. T cell exhaustion. Nat Immunol. 2011;12(6):492-9.

46. Almeida JR, Price DA, Papagno L, Arkoub ZA, Sauce D, Bornstein E, et al. Superior control of HIV-1 replication by CD8+ T cells is reflected by their avidity, polyfunctionality, and clonal turnover. J Exp Med. 2007;204(10):2473-85.

47. Yamamoto T, Price DA, Casazza JP, Ferrari G, Nason M, Chattopadhyay PK, et al. Surface expression patterns of negative regulatory molecules identify determinants of virus-specific CD8+ T-cell exhaustion in HIV infection. Blood. 2011;117(18):4805-15.

48. Wherry EJ, Blattman JN, Murali-Krishna K, van der Most R, Ahmed R. Viral persistence alters CD8 T-cell immunodominance and tissue distribution and results in distinct stages of functional impairment. J Virol. 2003;77(8):4911-27.

49. Fuller MJ, Zajac AJ. Ablation of CD8 and CD4 T cell responses by high viral loads. J Immunol. 2003;170(1):477-86

50. Day CL, Kaufmann DE, Kiepiela P, Brown JA, Moodley ES, Reddy S, et al. PD1 expression on HIV-specific T cells is associated with T-cell exhaustion and disease progression. Nature. 2006;443(7109):350-4

51. Trautmann L, Janbazian L, Chomont N, Said EA, Gimmig S, Bessette B, et al. Upregulation of PD-1 expression on HIV-specific CD8+ T cells leads to reversible immune dysfunction. Nat Med. 2006;12(10):1198-202.

52. Petrovas C, Casazza JP, Brenchley JM, Price DA, Gostick E, Adams WC, et al. PD-1 is a regulator of virus-specific CD8+ T cell survival in HIV infection. J Exp Med. 2006;203(10):2281-92

53. Zhang JY, Zhang Z, Wang X, Fu JL, Yao J, Jiao Y, et al. PD-1 up-regulation is correlated with HIV-specific memory CD8+ T-cell exhaustion in typical progressors but not in long-term nonprogressors. Blood. 2007;109(11):4671-8.
54. Tian X, Zhang A, Qiu C, Wang W, Yang Y, Qiu C, et al. The upregulation of LAG-3 on T cells defines a subpopulation with functional exhaustion and correlates with disease progression in HIV-infected subjects. J Immunol. 2015:194(8):3873-82.

55. Jones RB, Ndhlovu LC, Barbour JD, Sheth PM, Jha AR, Long BR, et al. Tim-3 expression defines a novel population of dysfunctional T cells with highly elevated frequencies in progressive HIV-1 infection. J Exp Med. 2008;205(12):2763-79.

56. Fromentin R, Bakeman W, Lawani MB, Khoury G, Hartogensis W, DaFonseca S, et al. CD4+ T cells expressing PD-1, TIGIT and LAG-3 contribute to HIV persistence during ART. PLoS Pathog. 2016;12(7):e1005761.

57. Ballbach $M$, Dannert A, Singh A, Siegmund DM, Handgretinger R, Piali L, et al. Expression of checkpoint molecules on myeloid-derived suppressor cells. Immunol Lett. 2017;192:1-6.

58. Zhang ZN, Yi N, Zhang TW, Zhang LL, Wu X, Liu M, et al. Myeloid-derived suppressor cells associated with disease progression in primary HIV infection: PD-L1 blockade attenuates inhibition. J Acquir Immune Defic Syndr. 2017;76(2):200-8.

59. Baggiolini M. Activation and recruitment of neutrophil leukocytes. Clin Exp Immunol. 1995;101(Suppl 1):5-6.

60. Baggiolini M, Loetscher P, Moser B. Interleukin-8 and the chemokine family. Int J Immunopharmacol. 1995:17(2):103-8.

61. Larsen CG, Anderson AO, Appella E, Oppenheim JJ, Matsushima K. The neutrophil-activating protein (NAP-1) is also chemotactic for T lymphocytes. Science. 1989;243(4897):1464-6

62. Sanmamed MF, Carranza-Rua O, Alfaro C, Onate C, Martin-Algarra S, Perez G, et al. Serum interleukin-8 reflects tumor burden and treatment response across malignancies of multiple tissue origins. Clin Cancer Res. 2014;20(22):5697-707

63. Alfaro C, Teijeira A, Onate C, Perez G, Sanmamed MF, Andueza MP, et al. Tumor-produced Interleukin-8 attracts human myeloid-derived suppressor cells and elicits extrusion of neutrophil extracellular traps (NETs). Clin Cancer Res. 2016:22(15):3924-36.

64. Kitano S, Postow MA, Ziegler CG, Kuk D, Panageas KS, Cortez C, et al. Computational algorithm-driven evaluation of monocytic myeloid-derived suppressor cell frequency for prediction of clinical outcomes. Cancer Immunol Res. 2014:2(8):812-21.

65. Kalathil S, Lugade AA, Miller A, lyer R, Thanavala Y. Higher frequencies of GARP(+)CTLA-4(+)Foxp3(+) T regulatory cells and myeloid-derived suppressor cells in hepatocellular carcinoma patients are associated with impaired T-cell functionality. Cancer Res. 2013;73(8):2435-44.

66. Pico de Coana Y, Masucci G, Hansson J, Kiessling R. Myeloid-derived suppressor cells and their role in CTLA-4 blockade therapy. Cancer Immunol Immunother. 2014;63(9):977-83.

67. Weide B, Martens A, Zelba H, Stutz C, Derhovanessian E, Di Giacomo AM, et al. Myeloid-derived suppressor cells predict survival of patients with advanced melanoma: comparison with regulatory T cells and NY-ESO-1- or melan-A-specific T cells. Clin Cancer Res. 2014;20(6):1601-9.

\section{Publisher's Note}

Springer Nature remains neutral with regard to jurisdictional claims in published maps and institutional affiliations.

Ready to submit your research? Choose BMC and benefit from:

- fast, convenient online submission

- thorough peer review by experienced researchers in your field

- rapid publication on acceptance

- support for research data, including large and complex data types

- gold Open Access which fosters wider collaboration and increased citations

- maximum visibility for your research: over $100 \mathrm{M}$ website views per year

At BMC, research is always in progress.

Learn more biomedcentral.com/submissions 